\title{
O CONTEXTO INFORMACIONAL CONTEMPORÂNEO: O CRESCIMENTO DA DESINFORMAÇÃO E SUAS MANIFESTAÇÕES NO AMBIENTE DIGITAL
}

\section{THE CONTEMPORARY INFORMATIONAL CONTEXT: THE SPREAD OF MISINFORMATION AND ITS MANIFESTATIONS IN THE DIGITAL ENVIRONMENT}

Leonardo Ripolla

José Claudio Matos ${ }^{b}$

\begin{abstract}
RESUMO
Introdução: $O$ artigo aborda o atual cenário da desinformação presente na web com o surgimento de terminologias como 'fake news', 'pós-verdade', 'deepfake', entre outros. Para tanto, primeiramente remete às discussões sócio-históricas que caracterizam o período de transformação da modernidade (pós-modernidade, alta modernidade, modernidade líquida). Apresenta também noções teóricas sobre a sociedade da informação e a cibercultura. Tal contextualização serve de fundamento para algumas definições sobre informação e desinformação. Objetivo: Apresentar o atual contexto informacional envolvendo a desinformação para sugerir novas dinâmicas no papel do profissional da informação e no campo de atuação da Ciência da Informação. Metodologia: Utiliza como modelo epistemológico, a teoria e o mapa conceitual de Luciano Floridi, por meio de uma pesquisa bibliográfica exploratória. Resultados e conclusão: Conclui que, perante este novo cenário, é imprescindível um olhar crítico na forma de lidar com a informação, buscando formas de assegurar a confiabilidade informacional. Tal cenário também propõe novos desafios e paradigmas aos profissionais da informação e à Ciência da Informação enquanto área do conhecimento.
\end{abstract}

Descritores: Desinformação. Disseminação da informação. Confiabilidade informacional. Fake news. Sociedade da informação.

\footnotetext{
a Mestre em Gestão de Unidades de Informação pelo Programa de Pós-Graduação em Gestão da Informação da Universidade do Estado de Santa Catarina (PPGInfo-UDESC). E-mail: leonardo_ripoll@hotmail.com

b Doutor em Filosofia pela Universidade de São Paulo. Professor adjunto da Universidade do Estado de Santa Catarina (UDESC). E-mail: doutortodd@gmail.com
} 


\section{INTRODUÇÃO}

O desenvolvimento do cenário das fake news nas mídias trouxe consigo a necessidade de novos questionamentos e paradigmas, especialmente nas áreas que trabalham diretamente com questões epistemológicas ligadas à informação. Atualmente presente de forma abundante em diversos meios, principalmente nas plataformas digitais, a informação virou sinônimo de tudo que habita a web - a 'grande rede' na qual considerável parte da população está presente, de uma forma cada vez mais indissociável de sua existência. Tal presença criou um 'ciberespaço' (LÉVY, 2010) ou uma 'infosfera' (FLORIDI, 2010) que produz constantemente fluxos informacionais e altera a forma como a humanidade lida com a sua realidade e com o seu conhecimento sobre o mundo. No entanto, o preenchimento de tais espaços pela vida política e social do indivíduo fez com que o fluxo informacional fosse composto de todo o tipo de manifestação comunicacional humana, incluindo aí, suas habilidades linguísticas relacionadas à mentira e ao ludíbrio.

A migração dos mais variados aspectos da vida humana para um ambiente caracterizado pelas virtualidades do digital, faz com que a informação passe a ter representações que já não condizem mais com seu caráter essencial: o ato de informar. É neste sentido que o surgimento de termos como 'fake news', 'pós-verdade', 'deepfake' e 'fatos alternativos' sugerem mais precisamente que a sociedade da informação está composta também de sintomas de um cenário de 'hiperinformação': e um deles é a identificação de porções significativas de desinformação.

A desinformação se propaga de forma fulminante na web, principalmente pelas redes sociais². Em um estudo publicado pela revista Science, Vosoughi,

1 O termo 'hiperinformação' aqui é entendido em consonância com Moretzsohn (2017): a alienação consequente do excesso de oferta informacional. Ou seja, está relacionado com sobrecargas cognitivas do indivíduo perante a quantidade contínua de informações recebidas em seu cotidiano.

${ }^{2}$ Neste artigo, as 'redes sociais' são entendidas como o que Recuero (2009) define para 'sites de redes sociais', também conhecidas por 'mídias sociais', como o Facebook, Twitter e Instagram. 
Roy e Aral (2018) verificaram que as notícias falsas são disseminadas de forma mais rápida e ampla do que as verdadeiras e alcançam um número muito maior de pessoas. Algumas explicações tecnológicas para tal fenômeno envolvem questões relacionadas às customizações de conteúdos ou perfis informacionais por empresas (criando o que Pariser (2011) denomina de 'filtros-bolha'), ao uso de bots nas interações sociais da web (conforme apresentado por Santana Júnior e Lima (2017)) e aos processos de ganho financeiro com cliques (conhecidos como 'clickbait' (ROCHLIN, 2017)).

Tal cenário é configurado por novas dinâmicas políticas e sociais, e demanda um reposicionamento de atuação dos profissionais da informação. À Ciência da Informação cabe a tarefa de se atualizar epistemologicamente, e discutir o papel da informação diante do cenário crescente de desinformação.

Este artigo tem o objetivo de abordar, sucintamente, o contexto informacional contemporâneo, principalmente no que tange à discussão sobre a desinformação e suas atuais manifestações no ambiente digital. Por meio de uma pesquisa bibliográfica exploratória, o estudo utilizou a epistemologia de Luciano Floridi como base de fundamentação conceitual sobre os fenômenos informacionais e também os pensamentos de Pierre Lévy, Manuel Castells, Jean-François Lyotard, Anthony Giddens e Zygmunt Bauman na elaboração contextual sociológica. A pesquisa foi complementada com a consulta sobre as terminologias contemporâneas relacionadas à desinformação (fake news, principalmente) em artigos científicos.

\section{TRANSIÇÃO DA MODERNIDADE E O DOMÍNIO DA INFORMAÇÃO}

O contexto informacional contemporâneo é caracterizado aqui como o presente estágio da sociedade da informação, no qual as redes sociais na internet possuem forte papel de influência na produção, disseminação e consumo da informação pela sociedade. No entanto, antes de as redes sociais se desenvolverem, o atual cenário já começava a se moldar por meio de mudanças e transições sócio-históricas relacionadas ao desenvolvimento da tecnologia e à reconfiguração da sociedade. 
A sociedade da informação surge enquanto conceito no mesmo cenário das discussões sobre o período histórico que surgiu após aquele que ficou conhecido como 'modernidade'.

\subsection{Pós-Modernidade, Alta Modernidade, Modernidade Líquida}

As discussões sociológicas sugerem que a época conhecida como 'modernidade' chegou ao fim (LYOTARD, 2004), está constituída de novas dinâmicas (BAUMAN, 2001) ou está em seu extremo (GIDDENS, 1991; 2002). No entanto, pode-se dizer que existe um consenso de mudança, de uma nova configuração da atividade humana, a partir do período que se inicia do meio para o final do século XX. Nessa configuração, a internet surge enquanto artefato de técnica humana, e a sociedade da informação emerge enquanto conceito representativo de um ambiente que centra suas ações no objeto informacional.

Segundo Jean-François Lyotard (2004), tal mudança é caracterizada por uma crise nos valores mantidos pela modernidade, especialmente no que o autor se refere como as 'grandes narrativas' do conhecimento. Para o autor, cada época vivida pela humanidade foi constituída por relatos específicos que explicavam o universo naquele dado momento e eram tomados como verdades absolutas, a fim de guiar o conhecimento. Cada vez que surge um novo relato, os anteriores são invalidados - processo resultante da crença implícita no progresso constante. Segundo Lyotard (2004), a partir do surgimento da ciência, por exemplo, a maior parte dos relatos anteriores tornou-se 'fábulas' perante os novos critérios. Porém, os próprios critérios científicos precisam ser legitimados por algum tipo de discurso, que passa a ser a filosofia do conhecimento em vigor. A pós-modernidade, assim, abdica de noções universais acerca das coisas, pois seriam 'totalizadoras' e excluiriam discursos que não estão na agenda de interesses do momento. Desta forma, também contesta a validade das instituições e o próprio conceito da palavra 'verdade'.

Conforme ocorre esse processo de 'desilusão' das narrativas da verdade, os ideais coletivos vão gradativamente cedendo espaço à busca da finalidade individual nas condutas. Essa finalidade individual, no entanto, também gera a 
percepção das diferenças entre os sujeitos, e é por isso que as grandes narrativas, que procuram dar uma voz única à multiplicidade de vozes componentes da sociedade, acabariam perdendo sua credibilidade. Além disso, a pós-modernidade discorre sobre o avanço tecnológico que demanda a instrumentalização do saber e a informatização da sociedade, e que prevê mudanças na regulagem e reprodução das informações (LYOTARD, 2004).

Embora seja um conceito muito utilizado em diversas pesquisas recentes (uma rápida pesquisa sobre o termo em qualquer base de dados revela uma grande quantidade de artigos), a pós-modernidade ainda não forma um consenso epistemológico. Giddens (1991), por exemplo, diz que a pósmodernidade sugere o fim do período moderno. Porém, segundo o autor, a humanidade não se encontra em um período 'além' da modernidade, e sim, vivenciando sua fase de radicalização. Para o autor, a nomenclatura correta seria 'alta modernidade', 'modernidade tardia' ou 'modernidade radicalizada'.

Giddens (2002) propõe que apesar do surgimento das instituições modernas ser reconhecido há certo tempo, é apenas no final do século $X X$ que se percebe que elas são mais complexas e problemáticas do que se havia suposto. $\mathrm{O}$ autor avalia que a crítica da modernidade faz parte de um processo de reflexão sobre ela e não de superação, como a ideia da pós-modernidade sugere. Segundo Giddens (1991), o que está em jogo no atual momento é um fenômeno de reflexividade inerente à própria modernidade. Se para Lyotard (2004) há uma transição de períodos, para Giddens (1991) há apenas uma 'conscientização' de um período que não só não acabou como também está em seu auge, em seu extremo, em sua forma mais radical e íntegra.

Já segundo Zygmunt Bauman (2001), 'modernidade líquida' seria a melhor expressão para caracterizar tal transição da modernidade. Para o autor, a leveza, a fluidez, a volatilidade e a constante transformação são características presentes nas relações dentro da atual sociedade. Bauman (2001), por comparação, chama então o início da modernidade de 'sólida'. Durante a modernidade sólida, as instituições sociais ainda manifestavam uma 'solidez' na sua relação com o indivíduo, agindo como referenciais na construção de sua identidade e na mediação de suas ações. Na modernidade líquida, ocorre a 
perda de tais pontos de referência e um crescimento do individualismo e autoafirmação do eu perante a sociedade.

Para Bauman (2001), a ideia da pós-modernidade, ou do 'fim da história', vem justamente do fato de que a velocidade dos acontecimentos sociais (ou históricos) já está no patamar do 'instantâneo'. O tempo rompe o espaço, e permite que nada mais seja exclusivamente local ou pertencente a certo momento. A tecnologia e a interconexão anulam as distâncias e promovem uma sensação de que as coisas estão sempre 'à disposição' o tempo todo, para o uso instantâneo e pontual. Enquanto isso, o consumo mercadológico aumenta, oferecendo cada vez mais alternativas descartáveis para usos momentâneos, em que a quantidade vai sobrepondo a qualidade. E assim também se configuram as relações humanas na modernidade líquida: fáceis, frágeis, leves, transitórias, fugazes e utilitárias.

Independentemente da terminologia utilizada, percebe-se nos discursos relatados a ideia de que uma mudança (com maior ou menor ênfase) vem acontecendo e tem relação com a quebra dos paradigmas que já não bastam para representar o atual momento da humanidade. Além disso, a tecnologia desponta como grande motor revolucionário do século $\mathrm{XX}$, transformando os meios de produção e a forma como o indivíduo se situa no mundo. Essa tecnologia, baseada em princípios matemático-computacionais, permite a produção massiva, contínua e crescente de informação.

\subsection{Cibercultura e Sociedade da INFormação}

Segundo Giddens (1991), a 'sociedade da informação' surge como um dos termos possíveis que anunciam um novo tipo de sistema social emergente da transição ocorrida no final do século XX. É a sociedade da informação que consolida a mudança socioeconômica da produção de bens industriais (frutos da Revolução Industrial) para a produção de bens informacionais. Castells (1999) descreve, com farta fundamentação empírica, este movimento de mudança na estrutura da sociedade, caracterizado, segundo o autor, pela elevação da informação à condição de fundamento da nova configuração social, em um 
sistema que ele denomina de 'informacionalismo', e que teria substituído o 'industrialismo' de etapas anteriores da modernidade. Castells (1999) também descreve cinco características principais da nova dinâmica social: é fundada na informação, é arquitetada na forma de redes, penetra e atua profundamente em todas as condutas humanas, é altamente flexível e moldável e, finalmente, conduz a uma convergência das tecnologias em um sistema integrado. Segundo ele, "a primeira característica do novo paradigma é que a informação é sua matéria-prima: são tecnologias para agir sobre a informação, não apenas informações para agir sobre a tecnologia, como foi o caso das revoluções tecnológicas anteriores" (CASTELLS, 1999, p. 108, grifo do autor).

De acordo com Luciano Floridi (2010), filósofo e pesquisador que desenvolveu a 'Filosofia da Informação', o que realmente caracteriza a atual noção de 'sociedade da informação' são as questões relacionadas ao que o autor denomina de 'revolução da informação'. Para o autor, desde a invenção da escrita, as tecnologias de informação e comunicação - TIC, que antes eram apenas sistemas de registro, passaram a ser, também, sistemas de comunicação (a partir da invenção da imprensa), e sistemas de processamento e produção (a partir da difusão dos computadores). Desde então, as sociedades têm se organizado e se desenvolvido em torno de serviços e questões informacionais. Floridi (2010) cita como exemplo que todos os países membros do G7 (Estados Unidos, Canadá, França, Alemanha, Itália, Japão e Reino Unido) possuem pelo menos $70 \%$ do seu Produto Interno Bruto (PIB) dependentes de bens intangíveis relacionados à informação, o que acaba os qualificando, de fato, como exemplos autênticos de 'sociedades da informação'. O impacto das TIC na atual sociedade é tão profundo, que Floridi (2010) afirma que elas estão 'reontologizando' o mundo, transformando sua natureza intrínseca.

Entender o mundo do ponto de vista informacional consiste em reordenar a realidade e a história em torno de um ambiente composto por dados, processos, agentes e conexões. Consiste em perceber que o desenvolvimento humano se dá por meio de interações informacionais que acontecem em seu sistema cognitivo e que, portanto, também afetam o desenvolvimento social. Consiste também em perceber que a realidade não é mais sempre tangível ou 
material, e está cada vez mais dinâmica e associada a um ambiente digital33.

Ainda que os primeiros passos da sociedade da informação tenham sido dados na primeira metade do século $\mathrm{XX}$, a sua verdadeira consolidação pode ser atribuída à popularização da internet na década de 1990, e à criação de um mundo digital decorrente da ocupação humana na rede, que Pierre Lévy (2010) denomina como 'ciberespaço' e 'cibercultura'. O ciberespaço passa a ser sinônimo do ambiente digital de criações e interações da sociedade, possibilitado pela web. Dentro dele, o homem continua a desenvolver suas manifestações (técnicas, sociais, artísticas, culturais, políticas, entre outras) de forma a produzir uma cibercultura.

Lévy (2010) destaca que, com o surgimento do hipertexto dentro da cibercultura, a produção e recepção da mensagem acontecem de forma sincronizada e no mesmo local: o ciberespaço. Segundo Lévy (2010), no ciberespaço há uma distribuição generalizada da informação, mas sem nenhum limite semântico, pois ela acaba sendo continuamente reconfigurada pelos seus usuários, dentro deste universo digital em constante transformação.

A tendência de crescimento do ciberespaço é inevitável. A cibercultura faz parte da mais recente atuação humana dentro da infosfera4; a representação máxima de como o ser humano tem deslocado cada vez mais suas relações (econômicas, sociais, educacionais, políticas, de lazer) do ambiente material para o informacional. Portanto, dentro da sociedade da informação, a cibercultura representa o modus operandi dos indivíduos conectados em rede. Tais repercussões estão cada vez mais sendo sentidas com a migração, cada vez maior, da vida e atividade humana para dentro da rede ${ }^{56}$. Floridi (2010) cita

3 Luciano Floridi desenvolve, nesse sentido, um extenso trabalho teórico denominado de 'Filosofia da Informação' (ver Floridi (2011) e (2018)).

${ }^{4}$ Floridi (2010) define a infosfera como o ambiente informacional da sociedade da informação que é constituído por processos informacionais, serviços e entidades - incluindo agentes informacionais e suas propriedades, interações e relações mútuas.

${ }^{5}$ Para Floridi (2010) a imersão na infosfera é cada vez maior conforme as gerações avançam e, portanto, os nativos digitais se sentirão cada vez mais excluídos e deslocados quando desconectados da infosfera, gerando possíveis crises existenciais.

${ }^{6}$ É importante ressaltar que a ocupação do ciberespaço se deu principalmente após o surgimento do que se convencionou chamar de 'web 2.0'. A web 2.0 corresponde ao estágio que a web alcançou no início dos anos 2000. Também chamada de social web, ficou caracterizada por possibilitar a criação de conteúdos na rede por todos os seus usuários, ação que até então 
que a tendência atual de fusão entre o digital e o analógico (representado por termos como a 'internet das coisas', os 'ambientes inteligentes' e a 'computação ubíqua') cria um cenário no qual, cada vez mais, a imersão digital se torna imperceptível e profunda.

Dentro deste contexto, a informação atinge seu potencial máximo de existência, até mesmo significando o que não é. A disseminação instantânea e massiva de dados e conteúdos informacionais, possibilitada pelo crescimento do ciberespaço e pela imersão na infosfera, faz também com que ações de desinformação surjam e se espalhem pela cibercultura.

\section{INFORMAÇÃO E DESINFORMAÇÃO}

A informação é um termo discutido em diversas áreas do conhecimento e atende a diversos contextos e utilizações. Por isso mesmo, é difícil encontrar um conceito único e definitivo do que ela representa. Sendo um termo com diversas definições, o consenso da literatura parece apontar justamente para essa ausência de um conceito unificado, como atestam, por exemplo, Floridi (2011) e Capurro e Hjorland (2007).

Floridi (2011) comenta que a informação é um fenômeno polimórfico e um conceito polissemântico, e, portanto, sua definição deverá levar em conta algumas considerações, como o nível de abstração adotado para a sua explicação. Capurro e Hjorland (2007), no artigo O conceito de informação, comentam que a distinção mais importante sobre o conceito de informação é aquela que separa e define a informação em dois caminhos principais: informação enquanto objeto ou coisa (dados de máquina, descrições objetivas) e informação enquanto signo (subjetiva ou interpretativa). Os autores também ressaltam que, neste último caso, o significado da informação é determinado pelos contextos social e cultural.

estava restrita a editores e administradores de sites. É a partir da web 2.0 que ocorre o crescimento de blogs, redes sociais (como o Twitter e o Facebook), Wikipédia e do jornalismo participativo. Na web 2.0, a participação, a interconexão e o compartilhamento tornam-se meios para a criação de uma 'inteligência coletiva' (NEWMAN et al., 2016; PRIMO, 2007). 
Floridi (2010), em seu livro Information: a very short introduction, tenta sumarizar em um mapa conceitual os diversos conceitos de informação, conforme algumas categorias e sua relação com os dados (Figura 1).

Figura 1 - Mapa de conceitos informacionais

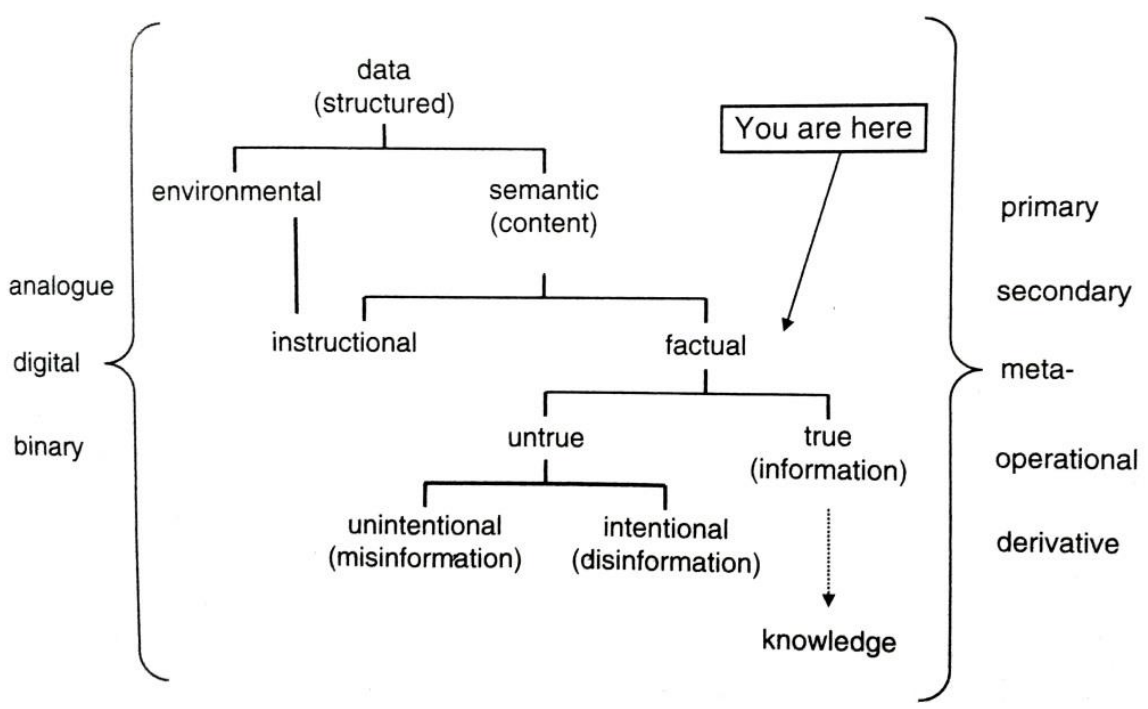

Fonte: Floridi (2010, p. 49).

A informação, de acordo com o mapa, se apresenta como a fase intermediária no percurso que tem os dados como ponto de partida e 0 conhecimento como ponto de chegada.

De acordo com o mapa, Floridi (2010) divide a informação em duas principais categorias: ambiental ou conteúdo semântico. A informação ambiental, segundo Floridi (2010), está relacionada aos dados que possuem significado, independentemente de terem sidos produzidos por um informante (por exemplo, a indicação de idade de uma árvore pelos anéis do seu tronco cortado ou as próprias impressões digitais dos seres humanos). Já a informação com conteúdo semântico exige que a informação dependa da existência de um vocabulário (linguístico ou não).

Como também visto no mapa, informações ambientais são sempre instrucionais, já as que possuem conteúdo semântico podem ser instrucionais ou factuais. A categoria instrucional trata de informações que repassam orientações ou descrições de algo, como, por exemplo, um manual de um equipamento, uma lista de afazeres, ou um código de programação. São 
informações, segundo Floridi (2010, p. 35, tradução nossa) "[...] que não se referem a uma situação, a um fato, ou a um estado das coisas [...]", portanto, não podem ser julgadas como verdadeiras ou falsas. Por sua vez, a informação factual é justamente aquela que se refere a um fato e, assim, é passível de julgamento.

Ainda de acordo com o mapa de Floridi (2010), a informação factual possui conteúdo semântico e é constituída de dados estruturados. No entanto, ela ainda precisa de mais um complemento: manifestar uma qualidade relacionada com a veracidade. A partir deste cenário se pode perguntar: O que acontece quando uma informação factual não é verdadeira? Segundo os critérios de Floridi (2010; 2011), especialmente o que ele chama de 'veridicalidade' (veridicality), ela deveria ser considerada como desinformação.

É importante perceber que a palavra 'desinformação', em português, muitas vezes é usada enquanto a tradução tanto de 'disinformation', como de 'misinformation', duas palavras que são conceitualmente distintas na língua inglesa. Conforme menciona Fallis (2010), ambas remetem ao contexto da informação imprecisa/incorreta (innacurate) e enganosa/ilusória (misleading). No entanto, misinformation corresponde a um engano originado na fonte emissora de forma não proposital (honest mistake), enquanto que na palavra disinformation existe uma intenção consciente da fonte em enganar (intended to deceive). O autor comenta que, sendo assim, é mais difícil identificar uma disinformation, já que ela é justamente produzida com a intenção de não ser identificada como tal.

Floridi (2010) corrobora com tais definições ao definir que a disinformation é a ação informacional intencional de um dado não verdadeiro. Já a misinformation é a ação informacional de um dado não verdadeiro feita por engano, sem saber que o dado não corresponde à verdade. Portanto, uma tradução adequada para o conceito de misinfomation poderia ser 'má informação' (o indivíduo estaria 'mal informado'). Tal diferença é apresentada também na Figura 1 acima.

A definição do dicionário Oxford para disinformation, por sua vez, está enunciada como "informação falsa que tem a intenção de enganar, 
particularmente a propaganda emitida por uma organização governamental para um poder rival ou a mídia" (OXFORD UNIVERSITY PRESS, 2018a, p.1, tradução nossa). Esta definição é caracterizada, principalmente, pela sua raiz política (enfatizada pelos exemplos, também políticos, descritos na página de definição do termo). No entanto, a definição encontrada no dicionário para a palavra misinformation, como "informação falsa ou imprecisa, particularmente aquela que deliberadamente tem a intenção de enganar" (OXFORD UNIVERSITY PRESS, 2018b, p. 1, tradução nossa), sugere que, para o dicionário, a diferença entre os termos está mais no seu contexto de uso (político ou não) do que em seu significado?.

Fallis (2010) cita que a disinformation possui algumas características básicas, baseadas no seu histórico de uso:

a) Comumente são atividades governamentais ou militares, apesar de também serem produzidas por outras organizações, ou mesmo por alguns indivíduos em particular;

b) Frequentemente é produto de uma fraude cuidadosamente planejada e tecnicamente sofisticada, apesar de também poder ser criada por uma mentira oral ou por uma simples edição na Wikipédia;

c) Nem sempre é divulgada diretamente a partir da fonte que a criou;

d) Frequentemente é divulgada verbalmente ou pela escrita, apesar de também poder ser criada por outros meios, como a manipulação de mapas ou imagens;

e) Frequentemente distribuída de forma bem abrangente, apesar de poder ser direcionada para pessoas ou organizações específicas;

f) A vítima do engano pretendido é geralmente uma pessoa ou grupo

\footnotetext{
${ }^{7}$ O projeto do dicionário Oxford, especialmente em sua versão digital, envolve a catalogação e a expressão do sentido das palavras do idioma inglês. Este processo assumiu uma importante proporção por causa do crescimento da língua dentro da expansão informacional ocasionada pela cibercultura. Em seu livro A informação, James Gleick (2013) discute a evolução dos significados e a geração de novos termos (como o próprio termo 'desinformação'), e também explora o caso do dicionário Oxford aqui mencionado. O uso do dicionário Oxford como referência, incorpora a consciência das mudanças na própria estrutura da linguagem, impulsionadas pela revolução informacional dos anos recentes.
} 
de pessoas, mas também pode ser direcionada para enganar máquinas, como os rastreadores de mecanismos de busca na web.

A desinformação, portanto, compreende, de forma geral, uma série de conceitos que são o oposto do ato de informar. Ou que, pelo menos, não pretendem atender ao critério de veracidade da informação. Demo (2000) discorre que a desinformação é um fenômeno natural da comunicação humana, uma vez que nossos sentidos têm limites na captação das informações, que, além disso, estão sujeitas a serem captadas conforme nossos interesses. Adverte, porém, que é fundamental preservar o senso crítico perante os processos de controle informacional.

Pinheiro e Brito (2014), ao comparar o conceito em inglês com suas representações no português, destacam três definições principais para 0 conceito de desinformação: ausência de informação, informação manipulada e engano proposital. Segundo os autores, o entendimento da desinformação como 'ausência de informação' está associado ao estado de ignorância e precariedade informacional, à ausência de cultura e de competência informacional, ao desprovimento de informações adequadas. Já o entendimento sobre 'informação manipulada' estaria relacionado a processos de alienação da população, para manter projetos de dominação política, ideológica ou cultural (sentido também partilhado por Demo (2000)). Sobre a desinformação enquanto 'engano proposital', Pinheiro e Brito (2014) retomam ao uso da desinformação no contexto Segunda Guerra Mundial. É quando a desinformação assume o sentido, já apresentado anteriormente, de ação proposital para enganar alguém. Fallis (2010) ressalta que, no presente momento, as novas tecnologias permitiram uma facilidade muito maior na criação e disseminação de desinformações e a questão da desinformação estaria associada, principalmente, a uma dimensão de 'qualidade' das informações.

As variações da desinformação transmitidas na comunicação cotidiana resultaram na criação ou ressurgimento de alguns termos pela mídia ou pelo discurso de personalidades públicas. A desinformação, assim, se reinventou a partir da criação da internet e das mídias sociais, e passou a gerar ramificações de categorias, aumentando sua complexidade. 


\subsection{Pós-Verdade, Fake News, Fatos Alternativos, Deepfake}

O atual estágio da sociedade da informação parece produzir um fenômeno inverso ao que acontecia em épocas anteriores à criação da internet. Se antes a informação era escassa, difícil de ser encontrada, ou limitada a lugares, materiais e mídias específicas (como as bibliotecas, os jornais e a televisão), hoje o avanço tecnológico permite que a informação esteja presente em todas as partes, e a ubiquidade do ciberespaço seja fortalecida a cada nova tecnologia portátil lançadå .

A produção, disseminação e consumo constantes de informação acabam por produzir um excesso de informações, causando o fenômeno da hiperinformação. A sobrecarga informacional, por fim, leva o indivíduo a perder o controle sobre aquilo que assimila. É o cenário ideal também para cada ator social utilizar a informação como melhor the convém no eterno palco das representações sociais e midiáticas.

Um termo que se desenvolve neste cenário é o conceito de 'pós-verdade'. Criado há mais de uma década, foi eleita palavra do ano em 2016 pelo dicionário Oxford. De acordo com o dicionário, o conceito de pós-verdade "denota ou se refere circunstâncias em que fatos objetivos são menos influentes na formação da opinião pública do que apelos à emoção e crença pessoal" (OXFORD UNIVERSITY PRESS, 2018c, p. 1, tradução nossa). Tal definição não se refere exatamente a um fenômeno novo. $\mathrm{O}$ discurso retórico que visa à conquista de seu público já era visto, por exemplo, no século XVI em Maquiavel e sua obra $O$ Príncipe (MACHIAVELLI, 1998). Algumas passagens dessa obra angariaram fama por sugerirem que um líder, em um espaço de poder e influência, pode e deve distorcer as informações disseminadas, conforme a conveniência do cenário político e em função de seus interesses. O que o conceito de pósverdade traz de novo é justamente uma adaptação de fenômenos como esse no contexto da sociedade da informação.

\footnotetext{
${ }^{8}$ Por exemplo, os termos 'internet das coisas' e 'internet de tudo' sugerem que a tendência é que todos os artefatos produzidos pela sociedade estejam cada vez mais integrados em rede, e sejam unidades emissoras/receptoras de informação.
} 
Sendo assim, pode-se perceber que a atual esfera de debate político, proporcionada pela web e pelas redes sociais, aumenta, em maior ou menor escala, o apelo à pós-verdade: determinadas posições políticas radicais acabam sendo assumidas por meio de crenças e ideologias como forma de lidar com situações de crise, levando a uma polarização e a uma 'guerra' informacional entre seus usuários. A pós-verdade parece ser eficaz principalmente diante do medo ou raiva causados por uma situação político-econômica fragilizada.

Já as 'fake news', correspondem possivelmente à categoria mais popular de desinformação atualmente. Traduzido pelo termo 'notícias falsas', as fake news são artigos jornalísticos que são intencionalmente e verificavelmente falsos, que enganam ou induzem o leitor ao erro (ALLCOTT; GENTZKOW, 2017). Para Lazer et al. (2018), fake news são informações fabricadas que imitam notícias apenas na forma, pois não são oriundas de nenhum grupo de mídia estruturado e, portanto, carecem de normas e processos editoriais que garantem a precisão e a credibilidade das informações. Apesar de ser um conceito que se popularizou no auge do uso das redes sociais, as fake news também surgiram há certo tempo (Allcott e Gentzkow (2017) relatam, por exemplo, artigos falsos do New York Sun em 1835). No entanto, o fenômeno da real 'explosão' das fake news surgiu no ambiente digital, a partir das possibilidades de compartilhamento fácil e rápido, feito por qualquer indivíduo dentro das redes sociais e dos aplicativos de troca de mensagens instantâneas.

Conforme as pesquisas realizadas por Vosoughi, Roy e Aral (2018) e Lazer et al. (2018), as notícias falsas mais disseminadas são relacionadas à política. Outras temáticas também difundidas são: terrorismo, desastres naturais, ciência, lendas urbanas, informações financeiras e bolsa de valores, vacinação e nutrição. Atualmente, no entanto, o termo fake news tem perdido seu sentido original e vem sendo usado como parte de discursos de pós-verdade, como por exemplo, para depreciar informações que sejam desfavoráveis à algum argumento.

Outro termo relativo à desinformação é aquele denominado de 'fatos alternativos' (alternative facts). O termo surgiu no início de 2017, por meio da fala de Kellyanne Conway (assistente do presidente norte-americano Donald Trump) 
sobre a declaração do secretário de imprensa da Casa Branca, Sean Spicer, a respeito do quantitativo de pessoas no momento da posse do presidente. De acordo com Rodden (2017), Conway utilizou o termo ao ser confrontada sobre a diferença existente entre a declaração de Spicer e as fotos da posse e estatísticas levantadas por profissionais. Para Conway, Spicer baseou sua afirmação em 'fatos alternativos' aos apresentados pelos especialistas até então.

Por último, o surgimento da 'deepfake' leva a desinformação a um patamar ainda mais complexo e refinado: a manipulação de vídeos em uma elaborada tecnologia de sobreposição de imagens. De acordo com Floridi (2018), técnicas de inteligência artificial permitiram o desenvolvimento de softwares de deepfake. Neles, a criação de vídeos falsos é feita substituindo elementos do vídeo, como as faces das pessoas que aparecem na gravação original por outras, que se tenham registros visuais digitais armazenados. Os casos típicos de deepfake envolvem a criação de pornografia com celebridades e de declarações de figuras políticas que nunca aconteceram.

A desinformação, portanto, assume diversas formas de transmissão, adequando-se às novas tecnologias e dinâmicas da comunicação presentes na sociedade da informação. Conhecer suas bases epistemológicas e seus mecanismos de ação é o primeiro passo para desenvolver ações que combatam a sua disseminação. Além disso, é importante que processos de leitura e pensamento críticos sejam desenvolvidos, permitindo ao indivíduo adquirir conhecimento com confiabilidade informacional9 .

\section{CONCLUSÃO}

Pós-verdade, fake news, deepfakes e fatos alternativos são, portanto, algumas das formas contemporâneas que a desinformação assumiu dentro do contexto da sociedade da informação e da cibercultura. São formas que, atreladas ao fenômeno da hiperinformação, se disseminam facilmente nas redes sociais e nos veículos de informação de forma geral. Além de instaurarem uma

\footnotetext{
${ }^{9}$ Tal discussão é devidamente ampliada em Leite (2018).
} 
crise dentro dos meios de comunicação, geram transtornos sociais e acabam deteriorando o próprio sentido da transmissão da informação.

A transição da modernidade, conforme discutido pelas análises sociológicas, fez com que conceitos que pareciam fortes e incontestáveis, como o de 'verdade' ou 'realidade', se demonstrem abertos a uma renovação de significados - demanda de uma revolução em curso, a da informação. Se existe algo que o atual contexto informacional pode levar a supor é que, o que existia no passado era uma 'ilusão da verdade'. Não pelo fato de a verdade não existir (como o relativismo exagerado pode sugerir), mas justamente por deixar mais explícito que as instituições que até então pareciam ser detentoras de uma verdade universal e total (como a Igreja, a Mídia, o Estado, os contratos sociais, as 'grandes narrativas'), são representantes de apenas uma parte da realidade. $\mathrm{E}$, invariavelmente, manipulam esta realidade para atender aos seus interesses (deliberados ou inerentes à sua natureza).

No entanto, a queda de tal ilusão causa uma desorientação inerente a uma forma de viver nova e desconhecida. $O$ cenário da desinformação, conforme sugere Demo (2000), prevê ações de controle, mas ao mesmo tempo um cuidado na utilização deste. A grande questão parece ser em como manter a liberdade associada à confiabilidade, no constante fluxo de informações. Pois, sem o devido cuidado, o controle de informações pode tornar-se facilmente sinônimo de censura e repressão.

O papel que o profissional da informação assume diante de tal cenário prevê tarefas múltiplas e um maior cuidado no atendimento das necessidades informacionais do seu público. É preciso disseminar informações confiáveis, mas também é preciso manter a liberdade de acesso a qualquer caminho informacional. No entanto, defende-se que desconsiderar a desinformação como uma forma de informação é uma ação necessária para superar a crise informacional dos meios digitais. É também uma forma da Ciência da Informação fortalecer seu campo de atuação e se concretizar epistemologicamente.

\section{REFERÊNCIAS}


ALLCOTT, Hunt; GENTZKOW, Matthew. Social media and fake news in the 2016 election. Journal of Economic Perspectives, v. 31, n. 2, p. 211-236, 2017. Disponível em:

https://web.stanford.edu/ gentzkow/research/fakenews.pdf. Acesso em: 06 jul. 2017.

BAUMAN, Zygmunt. Modernidade líquida. Rio de Janeiro: Zahar, 2001.

CAPURRO, R.; HJORLAND, B. O conceito de informação. Perspectivas em Cl, Belo Horizonte, v. 12, n. 1, 2007. Disponível em: http://portaldeperiodicos.eci.ufmg.br/index.php/pci/article/view/54/47. Acesso em: 06 out. 2016.

CASTELLS, Manuel. A sociedade em rede. São Paulo: Paz e Terra. 1999.

DEMO, Pedro. Ambivalências da sociedade da informação. Ciência da Informação, [S.I.], v. 29, n. 2, nov. 2000. Disponível em: http://revista.ibict.br/ciinf/article/view/885. Acesso em: 28 dez. 2016.

FALLIS, Don. A conceptual analysis of disinformation. In: ICONFERENCE, 4., 2009, Chapel Hill. Proceedings [...]. Illinois: Ideals, 2010. Disponível em: http://hdl.handle.net/2142/15205. Acesso em: 17 jan. 2018.

FLORIDI, Luciano. Artificial intelligence, deepfakes and a future of ectypes.

Philosophy \& technology, v. 31, n. 3, p. 317-321, sep. 2018. Disponível em: https://link-springer-com.ez46.periodicos.capes.gov.br/article/10.1007/s13347018-0325-3\#citeas. Acesso em: 20 dez. 2018.

FLORIDI, Luciano. Information: a very short introduction. Oxford: Oxford University Press, 2010.

FLORIDI, Luciano. Philosophy of information. 2018. Disponível em: http://www.philosophyofinformation.net/. Acesso em: 20 abr. 2018.

FLORIDI, Luciano. The philosophy of information. Oxford: Oxford University Press, 2011.

GIDDENS, Anthony. As consequências da modernidade. São Paulo: UNESP, 1991.

GIDDENS, Anthony. Modernidade e identidade. Rio de Janeiro: Zahar, 2002.

GLEICK, James. A informação: um conceito, uma história, uma enxurrada. São Paulo: Companhia das Letras, 2013.

LAZER, David M. J.; BAUM, Matthew A.; BENKLER, Yochai; BERINSKY, Adam J.; GREENHILL, Kelly M.; MENCZER, Filippo; METZGER, Miriam J.; NYHAN, Brendan; PENNYCOOK, Gordon; ROTHSCHILD, David; SCHUDSON, Michael; SLOMAN, Steven A.; SUNSTEIN, Cass R.; THORSON, Emily A.; WATTS, 
Duncan J.; ZITTRAIN, Jonathan L. The science of fake news: addressing fake news requires a multidisciplinary effort. Science, v. 359, n. 6380, p. 1094-1096, 09 mar. 2018. Disponível em:

http://science.sciencemag.org/content/359/6380/1094.full. Acesso em: 07 jun. 2018.

LEITE, Leonardo Ripoll Tavares. Confiabilidade informacional: a Filosofia da Informação e o desenvolvimento da leitura crítica no ambiente virtual. 129 p. Dissertação (Mestrado) - Universidade do Estado de Santa Catarina, Centro de Ciências Humanas e da Educação, Programa de Pós-Graduação em Gestão de Unidades de Informação, Florianópolis, 2018. Disponível em: http://sistemabu.udesc.br/pergamumweb/vinculos/000050/0000500b.pdf. Acesso em: 10 dez. 2018.

LÉVY, Pierre. Cibercultura. 3. ed. São Paulo: Ed. 34, 2010.

LYOTARD, Jean François. A condição pós-moderna. 8. ed. Rio de Janeiro: J. Olympio, 2004.

MACHIAVELLI, Niccolò. O príncipe. São Paulo: M. Fontes, 1998.

MORETZSOHN, Sylvia Debossan. "Uma legião de imbecis": hiperinformação, alienação e o fetichismo da tecnologia libertária. Liinc em Revista, Rio de Janeiro, v. 13, n. 2, p. 294-306, nov. 2017. Disponível em:

revista.ibict.br/liinc/article/view/4088. Acesso em: 05 jan. 2018.

NEWMAN, Russel; CHANG, Victor; WALTERS, Robert John; WILLS, Gary Brian. Web 2.0: the past and the future. International Journal of Information Management, v. 36, n. 4, p. 591-598, aug. 2016. Disponível em: https://wwwsciencedirect.ez46.periodicos.capes.gov.br/science/article/pii/S0268 401216301712 ?via\%3Dihub. Acesso em: 20 nov. 2018.

OXFORD UNIVERSITY PRESS. Disinformation. 2018a. Disponível em: https://en.oxforddictionaries.com/definition/disinformation. Acesso em: 24 jan. 2018.

OXFORD UNIVERSITY PRESS. Misinformation. 2018b. Disponível em: https://en.oxforddictionaries.com/definition/misinformation. Acesso em: 24 jan. 2018.

OXFORD UNIVERSITY PRESS. Word of the year 2016 is.... 2018c. Disponível em: https://en.oxforddictionaries.com/word-of-the-year/word-of-theyear-2016. Acesso em: 18 jan. 2018.

PARISER, Eli. The filter bubble: what the internet is hiding from you. New York: The Penguin Press, 2011.

PINHEIRO, Marta Macedo Kerr; BRITO, Vladimir de Paula. Em busca do significado da desinformação. DataGramaZero, v. 15, n. 6, p. A05, 2014. 
Disponível em: http://www.brapci.inf.br/index.php/article/download/51758.

Acesso em: 26 jan. 2018.

PRIMO, Alex. O aspecto relacional das interações na Web 2.0. E- Compós, Brasília, v. 9, p. 1-21, 2007. Disponível em:

http://www.ufrgs.br/limc/PDFs/web2.pdf. Acesso em: 15 maio 2017.

RECUERO, Raquel. Redes sociais na internet. Porto Alegre: Sulina, 2009.

ROCHLIN, Nick. Fake news: belief in post-truth. Library high tech, v. 35, n. 3 , p. 386-392, 2017. Disponível em:

https://www.emeraldinsight.com/doi/pdfplus/10.1108/LHT-03-2017-0062.

Acesso em: 20 set. 2018.

RODDEN, John. Donald and Winston at the Ministry of Alternative Facts.

Society, v. 54, n. 3, p. 215-217, jun. 2017. Disponível em: https://link-springercom.ez46.periodicos.capes.gov.br/article/10.1007/s12115-017-0127-8. Acesso em: 10 dez. 2018.

SANTANA JÚNIOR, Célio Andrade; LIMA, Camila Oliveira. O papel das máquinas sociais na formação de opinião em rede. Liinc em Revista, Rio de Janeiro, v. 13, n. 2, p. 307-322, nov. 2017. Disponível em:

http://revista.ibict.br/liinc/article/view/3940. Acesso em: 05 jan. 2018.

VOSOUGHI, Soroush; ROY, Deb; ARAL, Sinan. The spread of true and false news online. Science, v. 359, n. 6380, p. 1146-1151, 09 mar. 2018. Disponível em: http://science.sciencemag.org/content/359/6380/1146.full. Acesso em: 05 jun. 2018.

\title{
THE CONTEMPORARY INFORMATIONAL CONTEXT: THE SPREAD OF MISINFORMATION AND ITS MANIFESTATIONS IN THE DIGITAL ENVIRONMENT
}

\begin{abstract}
Introduction: The article discusses the current scenario of misinformation on the web with the emergence of terminologies such as 'fake news', 'post truth', 'deepfake', among others. Firstly, the paper alludes to the socio-historical discussions that characterize the period of transformation of modernity (postmodernity, high modernity, liquid modernity). It also presents theoretical notions about the information society and cyberculture. Such contextualization provides the basis for some definitions of information and misinformation. Objective: To present the current informational context involving the misinformation and suggest new dynamics about the role of the information professional and about the field of Information Science. Methodology: Using as an epistemological model, the theory and the conceptual map of Luciano Floridi, through an exploratory bibliographical research. Results and conclusion: Concludes that, faced with this new scenario, a critical look at how to deal with information is essential, looking for ways to ensure information reliability. This scenario also proposes new challenges and
\end{abstract}


paradigms for information professionals and for Information Science as an area of knowledge.

Descriptors: Misinformation. Information dissemination. Information reliability. Fake news. Information society.

\title{
EL CONTEXTO INFORMACIONAL CONTEMPORÁNEO: EL CRECIMIENTO DE LA DESINFORMACIÓN Y SUS MANIFESTACIONES EN EL AMBIENTE DIGITAL
}

\begin{abstract}
RESUMEN
Introducción: El artículo aborda el actual escenario de la desinformación presente en la web con el surgimiento de terminologías como 'fake news', 'posverdad', 'deepfake', entre otros. Para ello, primero remite a las discusiones socio-históricas que caracterizan el período de transformación de la modernidad (posmodernidad, alta modernidad, modernidad neta). También presenta nociones teóricas sobre la sociedad de la información y la cibercultura. Tal contextualización sirve de fundamento para algunas definiciones sobre información y desinformación. Objetivo: Presentar el actual contexto informacional envolviendo la desinformación para sugerir nuevas dinámicas en el papel del profesional de la información y en el campo de actuación de la Ciencia de la Información. Metodología: Utiliza como modelo epistemológico, la teoría y el mapa conceptual de Luciano Floridi, por medio de una investigación bibliográfica exploratoria. Resultados y conclusión: Concluye que, ante este nuevo escenario, es imprescindible una mirada crítica en la forma de lidiar con la información, buscando formas de asegurar la confiabilidad informacional. Tal escenario también propone nuevos desafíos y paradigmas a los profesionales de la información ya la Ciencia de la Información como área del conocimiento.
\end{abstract}

Descriptores: Desinformación. Diseminación de la información. Confiabilidad informacional. Fake news. Sociedad de la información.

Recebido em: 14/10/2019

Aceito em: $21 / 04 / 2020$ 